\title{
An elastoplastic constitutive relation of whisker-reinforced composite for meso damage: Part II - failure surfaces
}

\author{
H.Q. Liu *, N.G. Liang \\ Laboratory of Nonlinear Mechanics, Institute of Mechanics, Chinese Academy of Sciences, Beijing 100080, People's Republic of China
}

\begin{abstract}
An elastoplastic constitutive relation of whisker-reinforced composite was derived in Part I of this work [H.Q. Liu, N.G. Liang, An elastoplastic constitutive relation of whisker-reinforces composite for meso damage: Part I - formulation, J. Theoret. Appl. Fracture Mech. 33 (2000) 191-198]. Specific applications of this constitutive equation will be made to address mesoscale damage. Analyzed particularly is the relation between failure surface and dominant mechanism of brittle composites. The damage-induced anisotropy is exhibited using the damage distribution of whiskers in the orientation space. Qualitative agreement is obtained between the prediction and experimental results of carbon/epoxy laminates [S.R. Swanson, Introduction to Design and Analysis with Advanced Composite Materials, Prentice-Hall, Upper Saddle River, New Jersey, 1997]. (c) 2000 Elsevier Science Ltd. All rights reserved.
\end{abstract}

\section{Introduction}

The elastoplastic damage constitutive relation presented in Part I [1] can be applied to assess the overall elastoplastic damage behavior of whiskerreinforced composites. Aside from making some applications, emphasis will be placed on the failure behavior of brittle fiber-reinforced composite.

A failure surface of brittle composites being similar to the yield surface [3,4], could give a global description of the failure behavior. It can be used to analyze multi-axial failure criteria [5]. Failure modes of composites involve multiple mechanisms. Failure mode transition could depend on external loading [6] because of anisotropy. This is why failure mechanism independent of strength criteria may not be appropriate for high

\footnotetext{
${ }^{*}$ Corresponding author.

E-mail address: hliu@Inm.imech.ac.cn (H.Q. Liu).
}

performance composites under a wide variety of external loading conditions although convenient to use [7]. The relation between the governing failure mechanisms and failure surfaces may lead to a better understanding of failure modes and criteria.

An initial anisotropy can be described according to microstructure of composites. However, it is most difficult to include the anisotropy associated with the internal stress redistribution due to damage [8] and damage rate [9]. The anisotropy induced by damage and damage rate has been embodied in the effective stiffness tensor of the constitutive equation derived in Part I [1]. It is also reflected in the damage distributions of slip systems and fiber-bundles.

Part II of this work is concerned with applying the constitutive relation to specific cases. The analysis will be focused on the relation between failure surfaces and dominant failure mechanisms as well as damage-induced anisotropy. The 
predicted results are compared well with the experiment results of failure surfaces for carbon/epoxy laminates $[2,7]$.

\section{Constitutive equations in specific cases}

The elastoplastic damage constitutive relation includes constructing three types of elements that are assembled to represent the material model. Each type of elements may be a composite that has a specific constitutive equation.

\subsection{Metal-matrix composites}

The present model is composed of the elastic medium, equivalent slip systems and fiber-bundles. It is suitable for describing whisker-reinforced metal-matrix composites with meso-structures described by $\rho_{\mathrm{s}}$ and $\rho_{\mathrm{f}}$. Moreover, It is suited for analyzing fiber reinforcing/breaking, interface sliding/debonding and crystal sliding mechanisms. From [1], it can be stated that

$$
\begin{gathered}
\begin{aligned}
& \dot{\mathbf{S}}=\left\{V_{\mathrm{m}}\left(\mathbf{C}_{\mathrm{me}}^{(\mathrm{ef})}+\mathbf{C}_{\mathrm{ms}}^{(\mathrm{ef})}\right)^{-1}+V_{\mathrm{f}} \mathbf{K}_{\mathrm{f}}^{(\mathrm{ef})}\right\}: \dot{\mathbf{E}}, \\
&\left(\mathbf{C}_{\mathrm{me}}^{(\mathrm{ef})}\right)^{-1}= \mathbf{K}_{\mathrm{me}}^{(\mathrm{ef})} \\
&=\left(1-D_{\mathrm{me}}\right) \overline{\mathbf{K}}_{\mathrm{me}} \\
&-\frac{1}{2\left(1-D_{\mathrm{me}}\right)} \\
& \times\left(\frac{\mathrm{d} D_{\mathrm{me}}}{\mathrm{d} \mathbf{E}_{\mathrm{me}}} \otimes \mathbf{S}_{\mathrm{m}}+\mathbf{S}_{\mathrm{m}} \otimes \frac{\mathrm{d} D_{\mathrm{me}}}{\mathrm{d} \mathbf{E}_{\mathrm{me}}}\right), \\
& \mathbf{C}_{\mathrm{ms}}^{(\mathrm{ef})}=\int_{\Psi} \int_{\Phi} \frac{\rho_{\mathrm{s}}}{h_{\mathrm{s}}^{(\mathrm{eff})}} \mathbf{P}_{\mathrm{s}} \otimes \mathbf{P}_{\mathrm{s}} \mathrm{d} \Phi \mathrm{d} \Psi, \\
& \mathbf{K}_{\mathrm{f}}^{(\text {ef })}=\int_{\Omega} \rho_{\mathrm{f}} E_{\mathrm{f}}^{(\mathrm{ef})} \mathbf{P}_{\mathrm{f}} \otimes \mathbf{P}_{\mathrm{f}} \mathrm{d} \Omega,
\end{aligned}
\end{gathered}
$$

where $\mathbf{C}_{\text {me }}^{(\text {ef })}$ is the effective compliance tensor of the elastic medium, $\mathbf{C}_{\mathrm{ms}}^{(\mathrm{ef})}$ and $\mathbf{K}_{\mathrm{f}}^{(\mathrm{ef})}$, the effective compliance and stiffness tensors related with orientation distributions of equivalent slip systems and fiber-bundles. Note that
$\mathbf{P}_{\mathrm{s}}=\frac{1}{2}(\mathbf{m} \otimes \mathbf{n}+\mathbf{n} \otimes \mathbf{m})$,

$\mathbf{P}_{\mathrm{f}}=\mathbf{l} \otimes \mathbf{l}$

are orientation tensors of the slip system and fiberbundle, $\mathbf{m}$, a unit slip vector, $\mathbf{n}$, a unit normal vector of the sliding plane, and $\mathbf{l}$, a unit vector along the fiber-bundle. Volume fractions of the matrix and fiber-bundles satisfy the condition $V_{\mathrm{m}}+V_{\mathrm{f}}=1$.

Damage process of the composite depends on $\mathbf{K}_{\mathrm{me}}^{(\text {ef })}, \rho_{\mathrm{s}} / h_{\mathrm{s}}^{(\text {ef })}$ and $\rho_{\mathrm{f}} E_{\mathrm{f}}^{(\mathrm{ef})}$ which include the damage rate effect as well as their damage state.

Ignoring irreversibility due to the decrease of sliding strain $\left|\gamma_{\mathrm{s}}\right|$ and fiber strain $\left|\varepsilon_{\mathrm{f}}\right|$, the effective moduli $h_{\mathrm{s}}^{(\mathrm{ef})}$ and $E_{\mathrm{f}}^{\text {(ef) }}$ of slip system and fiberbundle can be expressed as

$h_{\mathrm{s}}^{(\text {ef })}=\left\{\begin{array}{l}\left(1-D_{\mathrm{s}}\right) \bar{h}_{\mathrm{s}}-\frac{\tau_{\mathrm{s}}}{1-D_{\mathrm{s}}} \frac{\mathrm{d} D_{\mathrm{s}}}{\mathrm{d} \gamma_{\mathrm{s}}}, \\ \text { when }\left|\gamma_{\mathrm{s}}\right| \geqslant \max \left(\left|\gamma_{\mathrm{s}}^{\mathrm{m}}\right|,\left|\gamma_{\mathrm{cr}}\right|\right) \text { and } \gamma_{\mathrm{s}} \mathrm{d} \gamma_{\mathrm{s}}>0 ; \\ \left(1-D_{\mathrm{s}}\right) \bar{h}_{\mathrm{s}} \\ \text { when }\left|\gamma_{\mathrm{s}}\right|<\max \left(\left|\gamma_{\mathrm{s}}^{\mathrm{m}}\right|,\left|\gamma_{\mathrm{cr}}\right|\right) \text { or } \gamma_{\mathrm{s}} \mathrm{d} \gamma_{\mathrm{s}} \leqslant 0 ;\end{array}\right.$

$E_{\mathrm{f}}^{(\mathrm{ef})}=\left\{\begin{array}{c}\left(1-D_{\mathrm{f}}\right) \bar{E}_{\mathrm{f}}-\frac{\sigma_{\mathrm{f}}}{1-D_{\mathrm{f}}} \frac{\mathrm{d} D_{\mathrm{f}}}{\mathrm{d} \mathrm{f}_{\mathrm{f}}} \\ \text { when }\left|\varepsilon_{\mathrm{f}}\right| \geqslant \max \left(\left|\varepsilon_{\mathrm{f}}^{\mathrm{m}}\right|,\left|\varepsilon_{\mathrm{cr}}\right|\right) \text { and } \varepsilon_{\mathrm{f}} \mathrm{d} \varepsilon_{\mathrm{f}}>0 \\ \left(1-D_{\mathrm{f}}\right) \bar{E}_{\mathrm{f}} \\ \text { when }\left|\varepsilon_{\mathrm{f}}\right|<\max \left(\left|\varepsilon_{\mathrm{f}}^{\mathrm{m}}\right|,\left|\varepsilon_{\mathrm{cr}}\right|\right) \text { or } \varepsilon_{\mathrm{f}} \mathrm{d} \varepsilon_{\mathrm{f}} \leqslant 0\end{array}\right.$

respectively. In Eqs. (7) and (8), $D_{\mathrm{s}}$ and $\tau_{\mathrm{s}}$ are the damage variable and resolved shear stress of the slip system, $\gamma_{c r}$, the critical failure strain of the weakest sliding system, and $\gamma_{s}^{\mathrm{m}}$, the maximum sliding strain. The damage variable and stress of the fiber-bundle are given by $D_{\mathrm{f}}$ and $\sigma_{\mathrm{f}}$. The smaller critical strain of the weakest fibers or the weakest-linking interface is $\varepsilon_{\text {cr }}$ and the maximum strain of the fiber-bundle is $\varepsilon_{\mathrm{f}}^{\mathrm{m}}$.

Without consideration of damage, i.e. $\mathbf{D} \equiv 0$ and $\dot{\mathbf{D}} \equiv 0$, the material model still contains three types of elements but limited to the elastoplasticity of whisker-reinforced metal-matrix composites. Thus, Eq. (1) becomes the elastoplastic constitutive equation

$\dot{\mathbf{S}}=\left\{V_{\mathrm{m}}\left(\overline{\mathbf{C}}_{\mathrm{me}}+\overline{\mathbf{C}}_{\mathrm{ms}}\right)^{-1}+V_{\mathrm{f}} \overline{\mathbf{K}}_{\mathrm{f}}\right\}: \dot{\mathbf{E}}$, 
where the effective compliance and stiffness tensors are degenerated into

$$
\overline{\mathbf{C}}_{\mathrm{ms}}=\int_{\Psi} \int_{\Phi} \frac{\rho_{\mathrm{s}}}{\bar{h}_{\mathrm{s}}} \mathbf{P}_{\mathrm{s}} \otimes \mathbf{P}_{\mathrm{s}} \mathrm{d} \Phi \mathrm{d} \Psi
$$

in which

$\bar{h}_{\mathrm{s}}= \begin{cases}\infty & \text { when } \tau_{-\mathrm{cr}}<\tau_{\mathrm{s}}<\tau_{+\mathrm{cr}}, \\ \bar{h}_{\mathrm{s}} & \text { when } \tau_{\mathrm{s}} \leqslant \tau_{-\mathrm{cr}} \text { or } \tau_{\mathrm{s}} \geqslant \tau_{+\mathrm{cr}}\end{cases}$

while

$\overline{\mathbf{K}}_{\mathrm{f}}=\int_{\Omega} \rho_{\mathrm{f}} \bar{E}_{\mathrm{f}} \mathbf{P}_{\mathrm{f}} \otimes \mathbf{P}_{\mathrm{f}} \mathrm{d} \Omega$.

Note that

$\bar{E}_{\mathrm{f}}=\left\{\begin{array}{lll}\bar{E}_{\mathrm{f}} & \text { when } \quad \varepsilon_{-\mathrm{cr}}<\varepsilon_{\mathrm{f}}<\varepsilon_{+\mathrm{cr}} \\ \bar{E}_{\mathrm{fs}} & \text { when } & \varepsilon_{\mathrm{f}} \leqslant \varepsilon_{-\mathrm{cr}} \text { or } \varepsilon_{\mathrm{f}} \geqslant \varepsilon_{+\mathrm{cr}} .\end{array}\right.$

The interface sliding is treated as pseudoplasticity fiber-bundle [10,11], that depends on the sliding modulus $\bar{E}_{\mathrm{fs}}$. The variation of $\tau_{ \pm \mathrm{cr}}$ and $\varepsilon_{ \pm \mathrm{cr}}$ can be determined from the sliding criteria of crystal and interface proposed in [1]. Eq. (9) was applied to predict the effect of constituents, orientation, and the coupling of crystal and interface sliding mechanisms on yield surfaces of the composites [4].

\subsection{Polymer composites}

Neglecting the crystal sliding mechanism, i.e. $h_{\mathrm{s}} \equiv \infty$, fiber breaking and interface debonding become the major physical mechanisms. The material model consisting of the elastic matrix and fiber-bundles would be suitable for fiber-reinforced polymer composites. Thus, Eq. (1) becomes

$\dot{\mathbf{S}}=\left\{v_{\mathrm{m}} \mathbf{K}_{\mathrm{me}}^{(\mathrm{ef})}+v_{\mathrm{f}} \mathbf{K}_{\mathrm{f}}^{(\mathrm{ef})}\right\}: \dot{\mathbf{E}}$.

Eq. (12) is the elastic damage constitutive equation that was applied to predict the effect of damage rate and fiber orientation distribution on the effective stiffness tensor and macro response. The predicted results of tensile modulus, strength, and failure strain of glass fiber-reinforced polypropylene laminates are in good agreement with the experimental data [12].

With $\mathbf{D} \equiv 0$ and $\dot{\mathbf{D}} \equiv 0$, Eq. (12) degenerates into the elastic constitutive equation, i.e.
$\dot{\mathbf{S}}=\left\{V_{\mathrm{m}} \overline{\mathbf{K}}_{\mathrm{me}}+V_{\mathrm{f}} \overline{\mathbf{K}}_{\mathrm{f}}\right\}: \dot{\mathbf{E}}$.

Eq. (13) was used to analyze the effect of the fiber orientation distribution and the mis-orientation on the stiffness tensor $[13,14]$.

\subsection{Polycrystalline metals}

In the case of $V_{\mathrm{f}}=0$, the model material degenerates into polycrystalline metals composed of the elastic medium and slip systems. Crystal sliding becomes the only physical mechanism. Therefore, Eq. (1) degenerates into the elastoplastic damage constitutive equation for metals, i.e.

$\dot{\mathbf{E}}=\left\{\mathbf{C}_{\mathrm{me}}^{(\mathrm{ef})}+\mathbf{C}_{\mathrm{ms}}^{(\mathrm{ef})}\right\}: \dot{\mathbf{S}}$.

Moreover, for $\mathbf{D} \equiv 0$ and $\dot{\mathbf{D}} \equiv 0$, Eq. (14) is reduces to that for the elastoplastic constitutive equation of metals

$\dot{\mathbf{E}}=\left\{\overline{\mathbf{C}}_{\mathrm{me}}+\overline{\mathbf{C}}_{\mathrm{ms}}\right\}: \dot{\mathbf{S}}$.

Based on Eq. (15), the evolution of yield surfaces [3], the elastoplastic response under out-ofphase cyclic deformation [15], and the deformation induced anisotropy [16] for polycrystalline metals could be predicted and the results tend to agree with experiments.

\section{Failure surface of brittle composites}

Experimental results show that the nonlinear behavior of brittle composites is not due to plasticity but due to the degradation of the elastic property [17]. Based on the present constitutive relation, the failure of brittle composites can be predicted only if the crystal and interface sliding criteria are replaced by failure criteria of slip systems and fiber-bundles.

Let $\tau_{\mathrm{s}}^{\mathrm{b}}$ denote the strength of slip systems and $\varepsilon_{\mathrm{f}}^{\mathrm{b}}$, the fiber-breaking strain. The failure surface of the composites can be determined by the internal envelope of all hyperplanes determined by $\mathbf{P}_{\mathrm{s}}: \mathbf{S}_{\mathrm{m}}=\tau_{\mathrm{s}}^{\mathrm{b}}$ and concomitant hyperplanes in the stress space with those determined by $\mathbf{P}_{\mathrm{f}}: \mathbf{E}=\varepsilon_{\mathrm{f}}^{\mathrm{b}}$. 
Fig. 1 shows the predicted failure surfaces and dominant regions related to different mechanisms. External boundaries of the shadow region are failure surfaces dominated by the crystal sliding mechanism, which corresponds to an ellipsoid in the $\left(S_{11}, S_{12}\right)$ space and a hexagon in the $\left(S_{11}, S_{22}\right)$ space. Internal boundaries of the shadow region are those dominated by the fiber breaking mechanism. They are the boundary of the overlap region of two ellipsoids in the $\left(S_{11}, S_{12}\right)$ space and a parallelogram in the $\left(S_{11}, S_{22}\right)$ space.

Evidently, two failure surfaces dominated by fiber breaking and crystal sliding mechanisms di-

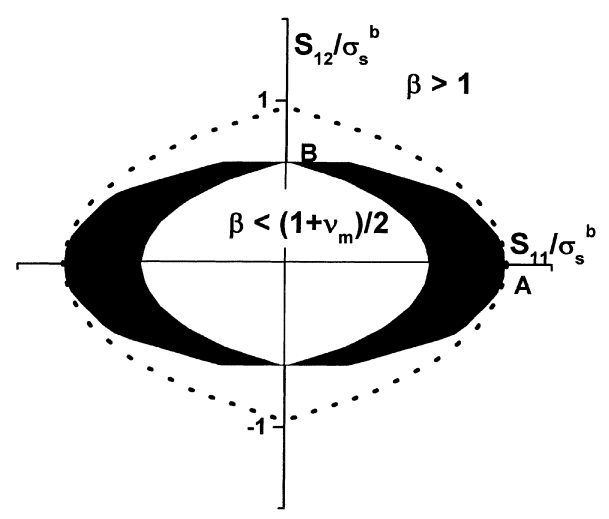

(a)

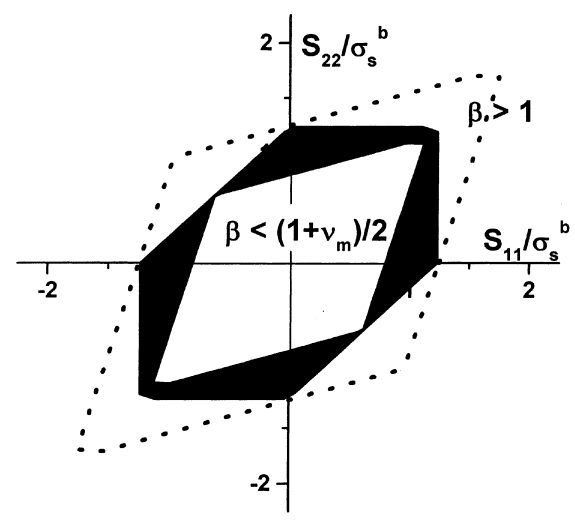

(b)

Fig. 1. Failure surfaces and dominant regions related with different mechanisms. (a) in $\left(S_{11}, S_{12}\right)$ space; (b) in $\left(S_{11}, S_{22}\right)$ space. vide the stress subspace into three parts. Each part is dominated by different mechanisms. The discrimination condition of different dominant regions can be derived.

Before failure, the composite is elastic, and the matrix and fiber-bundles share stress together.

According to Eq. (13), the matrix and fiberbundles satisfy

$S_{\mathrm{m}_{11}}=E_{\mathrm{m}} E_{11} \quad$ and $\quad S_{\mathrm{f}_{11}}=\frac{E_{\mathrm{f}}}{6} E_{11}$

in tension and

$S_{\mathrm{m}_{12}}=\frac{E_{\mathrm{m}}}{1+v_{\mathrm{m}}} E_{12} \quad$ and $\quad S_{\mathrm{f}_{12}}=\frac{2 E_{\mathrm{f}}}{15} E_{12}$

in torsion. By use of the compatible condition of deformation, the stresses carried by the matrix and fiber-bundles satisfy

$\mathbf{S}_{\mathrm{m}}=\mathbf{K}_{\mathrm{me}}: \mathbf{K}_{\mathrm{f}}^{-1}: \mathbf{S}_{f} \quad$ and $\quad \mathbf{S}_{\mathrm{f}}=\mathbf{K}_{\mathrm{f}}: \mathbf{K}_{\mathrm{me}}^{-1}: \mathbf{S}_{\mathrm{m}}$.

First, consider the failure surface dominated by the crystal sliding mechanism in the $\left(S_{11}, S_{12}\right)$ space, Fig. 1(a). This implies that the stress in the matrix would first reach its strength. For tension and torsion, the respective values

$S_{\mathrm{m}_{11}}=\sigma_{\mathrm{s}}^{\mathrm{b}} \quad$ and $\quad S_{\mathrm{m}_{12}}=\sigma_{\mathrm{s}}^{\mathrm{b}} / 2$,

where $\sigma_{\mathrm{s}}^{\mathrm{b}}=2 \tau_{\mathrm{s}}^{\mathrm{b}}$ is the tensile strength of the matrix. From Eqs. (16)-(18), the total stresses of the composite at the long and short axes of the failure surface are

$S_{11}=\left(V_{\mathrm{m}}+V_{\mathrm{f}} \frac{E_{\mathrm{f}}}{6 E_{\mathrm{m}}}\right) \sigma_{\mathrm{s}}^{\mathrm{b}}$,

$S_{12}=\left(V_{\mathrm{m}}+V_{\mathrm{f}} \frac{2\left(1+v_{\mathrm{m}}\right) E_{\mathrm{f}}}{15 E_{\mathrm{m}}}\right) \frac{\sigma_{\mathrm{s}}^{\mathrm{b}}}{2}$.

Note that $\left(S_{11}, 0\right)$ and $\left(0, S_{12}\right)$ correspond to points A and B in Fig. 1(a), respectively.

For failure dominated by fiber breaking, the stress in the fiber-bundles would first reach its strength. For tension and torsion, the respective values

$S_{\mathrm{f}_{11}}=\frac{\sigma_{\mathrm{f}}^{\mathrm{b}}}{6} \quad$ and $\quad S_{\mathrm{f}_{12}}=\frac{2}{15} \sigma_{\mathrm{f}}^{\mathrm{b}}$ 
are obtained. The tensile strength of fiber-bundles is $\sigma_{\mathrm{f}}^{\mathrm{b}}$ at the corresponding strain $\varepsilon_{\mathrm{f}}^{\mathrm{b}}$. From Eqs. (16)-(18), the total stresses of the composite at the long and short axes become

$S_{11}=\left(V_{\mathrm{m}} \frac{6 E_{\mathrm{m}}}{E_{\mathrm{f}}}+V_{\mathrm{f}}\right) \frac{\sigma_{\mathrm{f}}^{\mathrm{b}}}{6}$

$S_{12}=\left(V_{\mathrm{m}} \frac{15 E_{\mathrm{m}}}{2\left(1+v_{\mathrm{m}}\right) E_{\mathrm{f}}}+V_{\mathrm{f}}\right) \frac{2}{15} \sigma_{\mathrm{f}}^{\mathrm{b}}$

Let the long axes of the two failure surfaces equal. Equating Eqs. (20) and (23), there results

$\frac{\sigma_{\mathrm{f}}^{b} E_{\mathrm{m}}}{\sigma_{\mathrm{s}}^{\mathrm{b}} E_{\mathrm{f}}}=1$.

Eq. (25) gives the minimum upper bound of the region completely dominated by the crystal sliding mechanism. Let the short axes of two failure surfaces equal. Eq. (21) can thus be equated to Eq. (24) to give

$\frac{\sigma_{\mathrm{f}}^{\mathrm{b}} E_{\mathrm{m}}}{\sigma_{\mathrm{s}}^{\mathrm{b}} E_{\mathrm{f}}}=\frac{\left(1+v_{\mathrm{m}}\right)}{2}$.

Eq. (26) corresponds to the maximum lower bound of the region completely dominated by fiber breaking. Define a dimensionless quantity as

$\beta=\frac{\sigma_{\mathrm{f}}^{\mathrm{b}} E_{\mathrm{m}}}{\sigma_{\mathrm{s}}^{\mathrm{b}} E_{\mathrm{f}}}$,

where

$\frac{\left(1+v_{\mathrm{m}}\right)}{2} \leqslant \beta \leqslant 1$.

That is to say, for $\beta \leqslant\left(1+v_{\mathrm{m}}\right) / 2$, the failure is dominated by fiber breaking. Outside the region for $\beta \geqslant 1$, the crystal sliding mechanism dominates failure. However, for $\beta$ satisfying the inequality of Eq. (28), the failure depends on the coupling of both mechanisms. The inequality of Eq. (28) still holds in other sub-space, Fig. 1(b). It is coincident with the fact that most metal-matrix composites have a larger $\beta$ and their failure is dominated by the crystal sliding mechanism, while most polymer composites have a small $\beta$ where the failure is dominated by fiber-breaking. Certainly, debonding or delaminating will influence $\sigma_{\mathrm{s}}^{\mathrm{b}}$ and $\sigma_{\mathrm{f}}^{\mathrm{b}}$, and hence $\beta$. This may change the failure modes of the composite [18].

Take the carbon/epoxy laminating as an example [2]. Material constants are $E_{\mathrm{f}} / E_{\mathrm{m}}=66$, $v_{\mathrm{m}}=0.35, \sigma_{\mathrm{f}}^{\mathrm{b}} / \sigma_{\mathrm{s}}^{\mathrm{b}}=38.5$, and $V_{\mathrm{f}}=0.5$. They are taken from Ref. [2]. Also $\beta=0.583$ and $\beta_{l}=0.675$ are taken.

Fig. 2 shows failure surfaces of laminates with $[0 / \pm 45 / 90]_{n}$ lay-up in $\left(S_{11}, S_{22}\right)$ and $\left(S_{11}, S_{12}\right)$ spaces. Line-1 with $\beta<\beta_{l}$ in Fig. 2(a) is the failure surface dominated by fiber breaking. This is consistent with the experimental result $[2,7]$. Line-1 in Fig. 2(b) is different from that for the isotropic composite, Fig. 1(a). This is because only fibers in three directions play a part under combined axialtorsion loads.

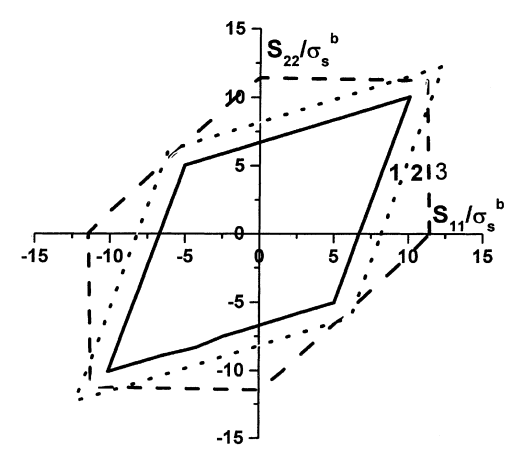

(a)

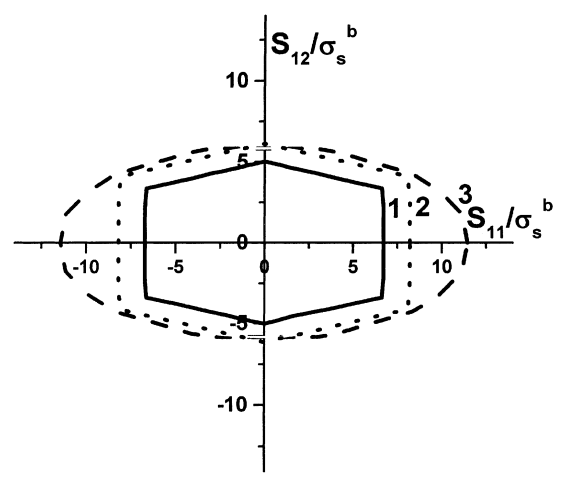

(b)

Fig. 2. Failure surfaces of laminates with $[0 / \pm 45 / 90]_{n}$ lay-up. (a) in $\left(S_{11}, S_{22}\right)$ space; (b) in $\left(S_{11}, S_{12}\right)$ space. 


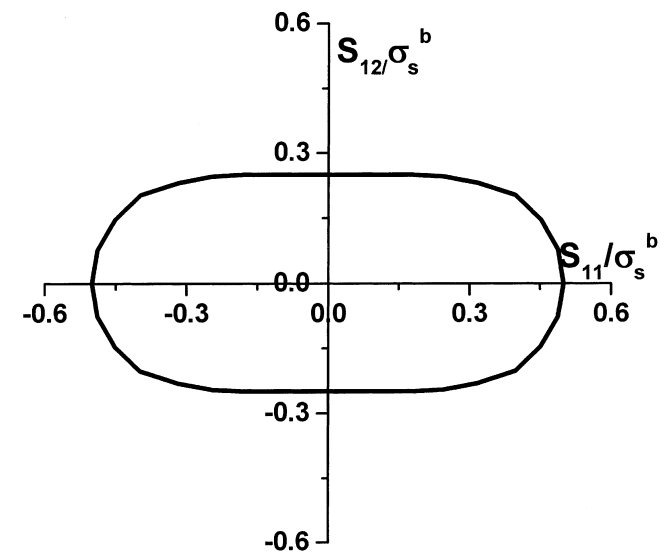

Fig. 3. Failure surface of laminate with $[90]_{n}$ lay-up in $\left\{S_{11}, S_{12}\right\}$ space.

Failure surfaces with $\beta=1$ (dash lines) are dominated by crystal sliding. Line- 2 with $\beta=$ $0.712>\beta_{l}$ is dominated by two mechanisms. Most part of the failure surface is dominated by fiber breaking except for those close to a pure shear stress state represented by dot lines. It can be seen that coupling effect moves failure mode transition close to a pure shear stress state for brittle composites. That is the reason why experimental data of failure surfaces of laminates are more scattered near a pure shear stress [2].

Fig. 3 shows the failure surface of laminate with $[90]_{n}$ lay-up in the $\left(S_{11}, S_{12}\right)$ space. It is completely controlled by the crystal sliding mechanism because the fiber in the $90^{\circ}$ direction has little contribution under combined axial-torsion loads. The predicted result is qualitatively in agreement with experimental data [2,7] except for the unsymmetry case that is not taken into account.

\section{Damage induced anisotropy of polymer compos- ites}

The damage-induced anisotropy of polymer composites exhibit not only the effect of damage on stiffness and macro response [12] but also the variation of meso-structure. Analyzed is the damage distribution of fiber-bundles of isotropic composites based on the elastic damage constitu- tive equation. The damage evolution of fiberbundle and matrix proposed in [12] are

$$
\begin{aligned}
& D_{\mathrm{f}}=\left\{\begin{array}{l}
0, \quad\left|\varepsilon_{\mathrm{f}}\right|<\left|\varepsilon_{\mathrm{cr}}\right|, \\
1-\exp \left\{-\lambda_{\mathrm{f}}\left[\left(\frac{\varepsilon_{\mathrm{f}}}{\varepsilon_{0}}\right)^{n_{\mathrm{f}}}-\left(\frac{\varepsilon_{\mathrm{cr}}}{\varepsilon_{0}}\right)^{n_{\mathrm{f}}}\right]\right\}, \\
\left|\varepsilon_{\mathrm{f}}\right| \geqslant\left|\varepsilon_{\mathrm{cr}}\right|,
\end{array}\right. \\
& D_{\mathrm{m}}=\lambda_{\mathrm{m}} v_{\mathrm{f}}^{n_{\mathrm{m}}} \bar{D}_{\mathrm{f}},
\end{aligned}
$$

where $\bar{D}_{\mathrm{f}}=\int_{\Omega} \rho_{\mathrm{f}} D_{\mathrm{f}} \mathrm{d} \Omega$

In Eqs. (29) and (30), $\lambda_{\mathrm{f}}$ and $\lambda_{\mathrm{m}}$ are damage coefficients, $n_{\mathrm{f}}$ and $n_{\mathrm{m}}$, damage exponents of the fiber-bundle and matrix, respectively.

Fig. 4 shows the distribution of $1-D_{\mathrm{f}}$ in the orientation space undergoing tensile deformation in the $z$-axis direction. When $D_{\mathrm{f}} \equiv 0$, it corresponds to a perfect unit hemisphere. The numerical result shows that damage begins from the fiber-bundles oriented in the tensile direction, and then spreads around.

Fig. 5 shows the distribution of $1-D_{\mathrm{f}}$ in the orientation space undergoing pure shear deformation. The maximum damage of fiber-bundles occurs in the $\pm 45^{\circ}$ directions in the $y z$-plane. It then spreads around.

It can be seen that the damage distribution of fiber-bundles is load-path dependent even for proportional loading.

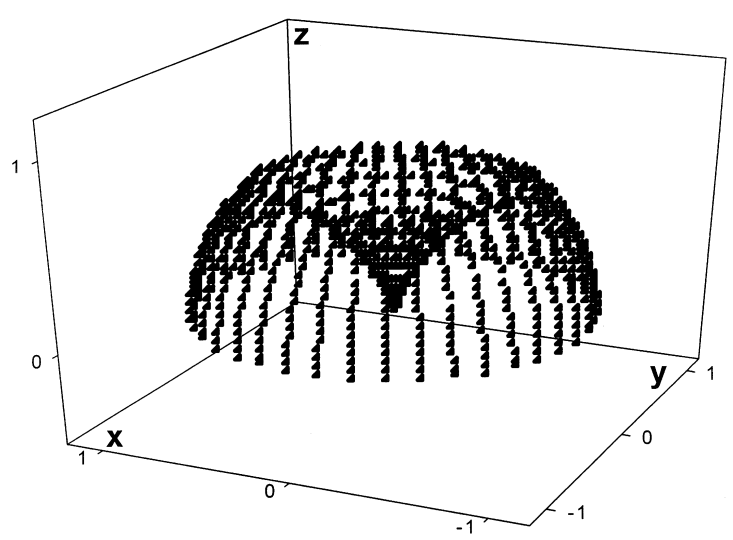

Fig. 4. Distribution of $1-D_{\mathrm{f}}$ in orientation space under tension. 


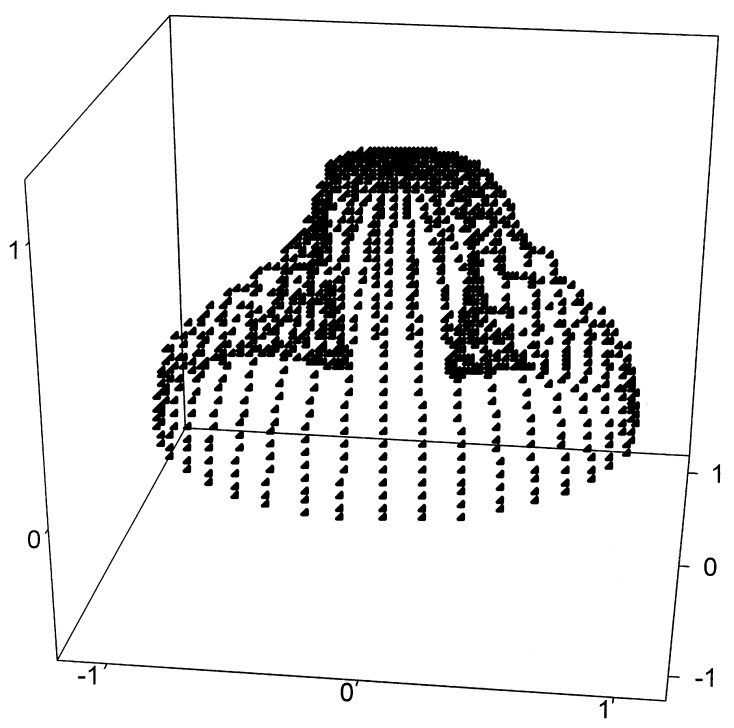

Fig. 5. Distribution of $1-D_{\mathrm{f}}$ in orientation space under pure shear.

\section{Discussion and conclusion}

The dominant mechanisms and failure surfaces are related. Theoretically, they provide an evaluation of the possible failure modes under complex loading. The conventional failure criteria, such as the maximum shear stress and the maximum fiber-direction strain criteria, may be valid for composites in a part of stress subspace, that is fiber-architecture dependent.

The initial anisotropy of whisker-reinforced composites can be described by the orientation distributions, $\rho_{\mathrm{f}}$ and $\rho_{\mathrm{s}}$. The damage-induced anisotropy is indicated by the distribution of $1-D_{\mathrm{f}}$ and $1-D_{\mathrm{s}}$ in the orientation space. Particularly, the distribution of $\rho_{\mathrm{s}} / h_{\mathrm{s}}^{(\mathrm{ef})}$ and $\rho_{\mathrm{f}} E_{\mathrm{f}}^{(\mathrm{ef})}$ exhibit the character of induced anisotropy associated with the evolution of microstructure, damage and damage rate.

The predicted results show that the present constitutive relation has the potential to be extended to other material models. In view of the negligible heterogeneity of short fibers with a large aspect ratio and dense distribution, the short-fiberreinforced composites may have similar behavior to the long-fiber-reinforced composites for statically-loaded deformation.

\section{Acknowledgements}

This research work has been supported through the Grant No. 19872065 and No. 19732060 from the National Natural Science Foundation of China and granted by Chinese Academy of Sciences (KJ951-1-201).

\section{References}

[1] H.Q. Liu, N.G. Liang, An elastoplastic constitutive relation of whisker-reinforced composite for meso damage: Part I - formulation, J. Theoret. Appl. Fracture Mech. 33 (2000) 191-198.

[2] S.R. Swanson, Introduction to Design and Analysis with Advanced Composite Materials, Prentice-Hall, Upper Saddle River, New Jersey, 1997.

[3] N.G. Liang, H.Q. Liu, T.C. Wang, A meso elastoplastic constitutive model for polycrystalline metals based on equivalent slip systems with latent hardening, Sci. China A 41 (8) (1998) 887-896.

[4] H.Q. Liu, N.G. Liang, A physical mechanism based elastoplastic constitutive theory of whisker-reinforced metalmatrix composites: part I. theory and part II. prediction, in: B. Xu, M. Tokuda, X. Wang (Eds.), The Fourth International Symposium on Microstructures and Mechanical Properties of New Engineering Materials, International Academic Publishers, Beijing 1999, pp. 63-74.

[5] M. Chaudonneret, Fatigue life prediction of components: an analysis of the different working steps, in: A Pineau, G. Cailletaud, T.C. Lindley (Eds.), Multiaxial Fatigue and Design, ESIS 21, Mechanical Engineering publications, London, 1996, pp. 489-497.

[6] J.Z. Wang, D.F. Socie, Failure strength and damage mechanisms of E-glass/epoxy laminates under in-plane biaxial compressive deformation, J. Compos. Mater. 27 (1993) 40-58.

[7] G.E. Colvin, S.R. Swanson, Characterization of the failure properties of IM7/8551-7 Carbon/epoxy under multiaxial stress, ASME J. Engrg. Mater. Technol. 112 (1990) 61-67.

[8] K.L. Reifsnider, Fatigue of composite materials, Composite Material Series 4, Elsevier, Amsterdam-Oxford-New York-Tokyo, 1991.

[9] H.Q. Liu, N.G. Liang, A physical-mechanism-based anisotropic damage-rate-dependent constitutive equation, in: B. Xu, W. Yang (Eds.), The Second Asia-Pacific Symposium on Advances in Engineering Plasticity and its application, International Academic Publishers, Beijing, 1994, pp. 155-160.

[10] X.Y. Liu, W.D. Yan, N.G. Liang, A pseudo-plastic engagement effect on the toughening of discontinuous fiber-reinforced brittle composites, Metals and Mater. 4 (3) (1998) 242-246.

[11] N.G. Liang, Q.J. Liu, J. Li, H.T.Song, A chain-network model simulating macro mechanical behavior and micro 
damage evolution of in situ reinforced ceramics, in: T.Abe, T. Tsuta (Eds.), Advance in Engineering Plasticity and its Applications, Permamon, Tokyo, 1996, pp. 141-147.

[12] H.Q. Liu, N.G. Liang, M.F. Xia, Modeling and mesoscopic damage constitutive relation of brittle shortfiber-reinforced composites, Sci. China E 42 (5) (1999) 530-540.

[13] A.L. Kalamkarov, H.Q. Liu, A new model for the multiphase fiber-matrix composite materials, Composites B 29 (5) (1998) 643-653.

[14] A.L. Kalamkarov, H.Q. Liu, D.O. MacDonald, Experimental and analytical studies of smart composite reinforcement, Composites B 29 (1) (1998) 21-30.

[15] H.Q. Liu, N.G. Liang, Mechanical-property parameters of polycrystalline metal and prediction of stress-strain responses under out-of-phase cyclic deformation, in: Wang and $\mathrm{Xu}$ (Eds.), The First Asia-Oceania Symposium on Plasticity, Beking University Press, Beijing, China, 1993, pp. 438-445.

[16] H.Q. Liu, K. Hutter, On a meso-elastoplastic constitutive equation with application to deformation-induced anisotropy of a polycrystalline aggregate, Arch. Mech. 48 (1) (1996) 53-65.

[17] Audoin, B. Baste, S. Ultrasonic, Evaluation of Stiffness tensor changes and associated anisotropic damage in a ceramic matrix composite, J. Appl. Mech. 61 (1994) 309316.

[18] L.V. Smith, S.R. Swanson, Micro-mechanics parameters controlling the strength of braided composites, Compos. Sci. Tech. 54 (1995) 177-184. 